\title{
Phosphorus and Other Impurities in Australian Iron Ores
}

\author{
C.M. MacRae*, N.C. Wilson*, M.I. Pownceby* and P.R. Miller** \\ * Microbeam Laboratory, CSIRO Process Science and Engineering, Clayton South, Vic, 3169 \\ ** Monash Centre for Electron Microscopy, Monash University, Clayton Campus, Vic, 3800
}

Phosphorus is a major contaminant in steelmaking and current specifications for iron ore, the feedstock used in steelmaking, requires ores averaging less than $0.08 \% \mathrm{P}$ (bulk). In Australia, the majority of iron ore feedstock production is a blend of low-P $(<0.05 \% \mathrm{P})$ hematite-rich ores and more common high-P $(>0.10 \% \mathrm{P})$ goethite-rich ores. The former is the major component of the blend, but reserves of this ore type are limited. Economically viable techniques for the removal of $\mathrm{P}$ from the goethite-rich ores will therefore become increasingly important to Australia as reserves of low-P ores continue to decrease.

Previous work has shown that $\mathrm{P}$ can occur in Australian iron ores in two ways: as microscopic inclusions of the mineral apatite $\mathrm{Ca}_{5}\left(\mathrm{PO}_{4}\right)_{3}(\mathrm{OH})$ or present at low levels within the hydrated iron oxide, goethite $\mathrm{FeOOH}^{1}$. Apatite is generally in low abundance in iron ores and $\mathrm{P}$ in this form is easily removed. On the other hand, goethite containing $\mathrm{P}$ is much more abundant and difficult to remove without discarding significant quantities of valuable iron as well. The goethite forms during supergene metasomatic enrichment of the ore causing the formation initially of ferrihydrite $\left[\mathrm{FeO}(\mathrm{OH})_{3} . n \mathrm{H}_{2} \mathrm{O}\right]$, which is subsequently dehydrated and recrystallised to form goethite. Evidence suggests that $\mathrm{P}$ is typically associated with other impurity elements such as Si and Al.

Characterisation of high-P iron ores by electron microprobe was carried out to measure maximum $\mathrm{P}$ and other impurity element contents. The aim was to determine possible elemental associations and, using this knowledge, to speculate on possible P-bearing species that may be present (e.g. $\left[\mathrm{PO}_{4}\right]^{2-}$ or $\left.\left[\mathrm{AlPO}_{4}\right]^{-}\right)$. To identify high-P grains, coarse mapping was initially performed at $15 \mathrm{kV}$ with steps of $2 \mu \mathrm{m}$ and a relatively short acquisition time of $30 \mathrm{~ms}$, using a JEOL 8500F equipped with WD spectrometers. The maps were then inspected using Chimage software ${ }^{2}$. Candidate grains containing elevated $\mathrm{P}$, typically up to $\sim 1 \mathrm{wt} \%$ or greater, were then selected for high resolution mapping performed at low voltage, usually $7 \mathrm{kV}$ with steps sizes of between 100-200 nm. The dwell times were extended to between 80 and $100 \mathrm{~ms}$ to increase the sensitivity enabling elemental associations to be confirmed. An example of a high resolution map is given in Figure 1, showing a high-P region containing hematite and goethitic iron oxides. The Fe, Al, and P elemental distribution map shows two distinct forms of phosphorus enrichment occurring along hematite grain boundaries, ranging in size from tens of nanometres through to several microns. Subsequent quantitative microanalysis at 7 $\mathrm{kV}$ was performed on the $\mathrm{P}$ containing regions to determine elemental associations (Figure 2). The analyses fell into two groupings: the first showed a combination of $\mathrm{P}$ and $\mathrm{Al}$ (average $\mathrm{P} \sim 1.15 \mathrm{wt} \%$ and $\mathrm{Al} \sim 0.75 \mathrm{wt} \%$ ) while the second showed mainly elevated $\mathrm{P}$ with low Al (average $\mathrm{P} \sim 1.25 \mathrm{wt} \%$ \& $\mathrm{Al} \sim 0.25 \mathrm{wt} \%$ ). The high-P regions were all contained in a geothitic matrix, however, the different Al:P ratios within different grains suggests at least two separate episodes of goethite formation. During the quantitative analyses it was noted that while the theoretical value for oxygen in goethite is $36 \mathrm{wt} \%$, the analyses averaged only $32 \mathrm{wt} \%$ for oxygen. Some beam damage was evident on the surface after the mapping at $7 \mathrm{kV}$ and we suspect this may lead to the low oxygen contents - caused by the volatilisation and removal of the bound water. 
Focussed ion beam milling is being used to prepare samples from areas identified as high in $\mathrm{P}$ for study by transmission electron microscopy to better understand the local chemical and structural environment of the P. In addition, Quantum Mechanical modelling of the bulk structure and properties of goethite is being carried out to see whether phosphate (or other) species are likely to be incorporated into the surface of the growing/precipitating goethite crystal or whether the $\mathrm{P}$ is structurally incorporated into the crystal lattice. The modelling will aid in completing the understanding of the structural incorporation and enable tailored removal processes to be developed.

In this presentation, we will discuss our high-resolution electron microprobe study of P-rich iron oxides, the element associations with $\mathrm{P}$, together with quantum mechanical models of the atomic arrangement of $\mathrm{P}$ in goethite.

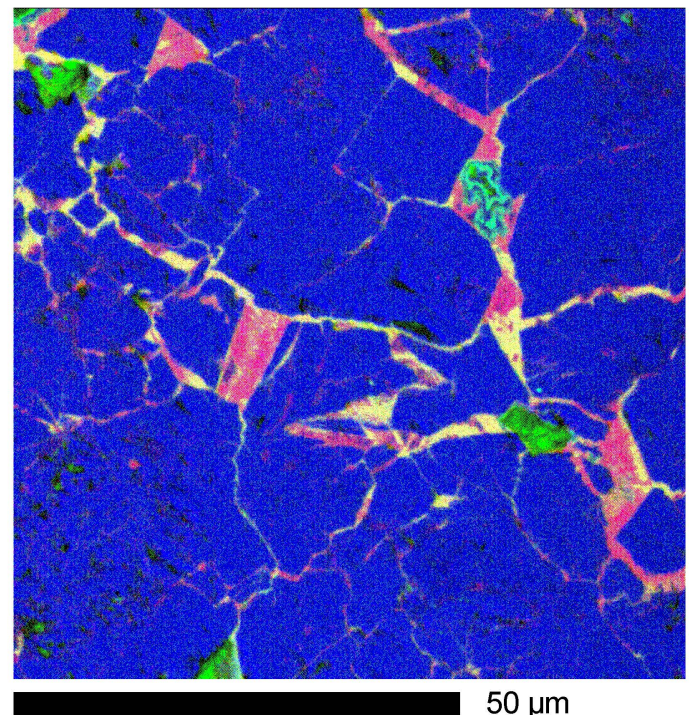

Figure 1, a high resolution map showing high$\mathrm{P}$ (red) and high $\mathrm{P}+\mathrm{Al}$ (yellow) goethitic material precipitated at hematite (blue) grain boundaries. The map was collected at $7 \mathrm{kV}$, $100 \mathrm{nA}$ with $200 \mathrm{~nm}$ pixels and $80 \mathrm{~ms}$ dwell time.

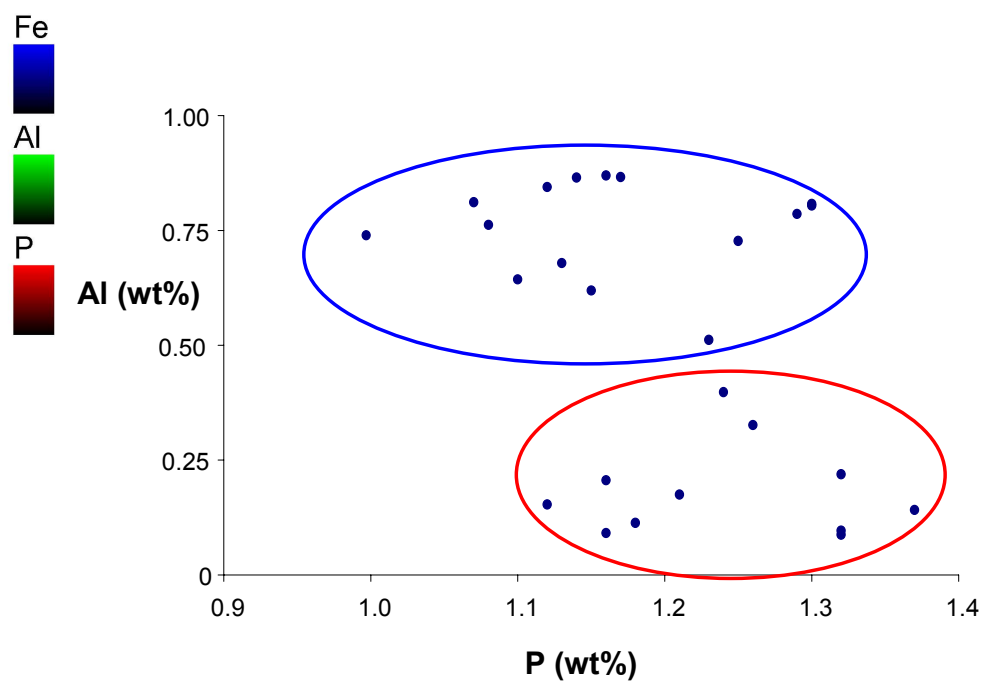

Figure 2, quantitative microanalysis of the two forms of $\mathrm{P}$ incorporation into goethite. The $\mathrm{P}$ can be incorporated with both low amounts of Al (average $\sim 0.25 \quad \mathrm{wt} \% \quad \mathrm{Al}$ ) and higher amounts (average $\sim 0.75 \mathrm{wt} \% \mathrm{Al}$ ) indicating two separate goethitic compositional types.

Acknowledgement: This work was supported by the CSIRO Minerals Down Under Flagship.

\section{References:}

[1] Dukino, R.D., England, B.M. and Kneeshaw, M (2000), Trans. IMM., Section B: Applied Earth Sciences, p. B168-B176.

[2] Harrowfield, I. R., MacRae, C.M. and Wilson, N.C. (1993) Proceedings of the $27^{\text {th }}$ Annual Microbeam Analysis Society Meeting (1993), p. 547-548. 